\title{
Behavioral Evidence for a Glucose Polymer Taste Receptor That Is Independent of the T1R2+3 Heterodimer in a Mouse Model
}

\author{
Yada Treesukosol, ${ }^{1,2}$ Kimberly R. Smith, ${ }^{1,2}$ and Alan C. Spector ${ }^{1,2}$ \\ ${ }^{1}$ Department of Psychology and 2 Program in Neuroscience, Florida State University, Tallahassee, Florida 32306-4301
}

\begin{abstract}
Although it is clear that the heterodimer formed by the T1R2 and T1R3 proteins serves as the primary taste receptor for sweeteners, there is growing evidence that responses to glucose polymers may be mediated by a different taste receptor. Here we report that although T1R2 knockout (KO) and T1R3 KO mice displayed severely impaired responding to glucose, maltose, and maltotriose in an initial session of a brief-access taste test ( $5 \mathrm{~s}$ trials, $25 \mathrm{~min}$ sessions) relative to wild-type (WT) mice, they subsequently increased their licking as a function of concentration for maltose and maltotriose with continued testing, presumably due to associating weak oral cues with positive post-ingestive consequences. Interestingly, these KO mice displayed relatively normal concentration-dependent licking to Polycose, a mixture of glucose polymers, even in the first session. Importantly, the experience-dependent increase in responsiveness to the sugars observed with the T1R2 and T1R3 single K0 mice was not statistically significant in the T1R2/3 double KO mice. The double KO mice, however, still displayed significant concentration-dependent responding to Polycose in the first test session, albeit lick rates were slightly lower than those seen for WT mice, perhaps because small amounts of glucose, maltose, and maltotriose found in Polycose were enhancing the signal in WT mice or because T1R2 or T1R3 can possibly heteromerize with another protein to form a fully functional glucose polymer receptor. These findings provide behavioral evidence that glucose polymers, with an optimal chain length greater than three glucose moieties, stimulate a taste receptor independent of the T1R $2+3$ heterodimer.
\end{abstract}

\section{Introduction}

Although evidence in the literature supports the view that the heterodimer of the T1R2 and T1R3 proteins found in taste bud cells serves as the taste receptor for sweeteners (see Chandrashekar et al., 2006), questions have been raised as to whether there are other receptors to which longer chain glucose polymers may bind (Sclafani, 1987, 2004b; Bachmanov and Beauchamp, 2007). This hypothesis is based primarily on behavioral and electrophysiological studies demonstrating that rodents respond to Polycose, a mixture of glucose polymers, in a manner that can be distinguished from their responses to simple sugars and other sweeteners (see Sclafani, 1987, 1991).

If "sweeteners" bind to T1R2+3, but sucrose and Polycose elicit distinct taste qualities, it would follow that the T1R2+3

\footnotetext{
Received April 30, 2011; revised July 24, 2011; accepted Aug. 4, 2011.

Author contributions: Y.T. and A.C.S. designed research; Y.T. and K.R.S. performed research; Y.T. and A.C.S. analyzed data; Y.T. and A.C.S. wrote the paper.

This work was supported by NIH Grant R01-DC004574 (A.C.S.). We thank Thomas Shakar and Jillian Gregson for their technical help in this experiment. We also thank Dr. Charles Zuker for generously supplying the T1R2 and T1R3 knock-out breeding pairs. Portions of this work were presented in a dissertation in partial fulfillment of a Doctor of Philosophy degree from Florida State University and were also presented at the 18th Annual Meeting of the Society for the Study of Ingestive Behavior, Pittsburgh, PA, July 2010, and the 33rd Annual Meeting of the Association of Chemoreception Sciences, St. Pete Beach, FL, April 2011.

The authors declare no competing financial interests.

Correspondence should be addressed to Dr. Alan C. Spector, Department of Psychology, Florida State University, 1107 West Call Street, P.0. Box 3064301, Tallahassee, FL 32306-4301. E-mail: spector@psy.fsu.edu.

Y. Treesukosol's present address: Department of Psychiatry and Behavioral Sciences, Johns Hopkins University School of Medicine, Baltimore, Maryland 21205.

DOI:10.1523/JNEUROSCI.2179-11.2011

Copyright $\odot 2011$ the authors $\quad 0270-6474 / 11 / 3113527-08 \$ 15.00 / 0$
}

heterodimer is not involved in the mediation of Polycose taste. In support of this hypothesis, polymorphisms in the Tas1r3 gene that appear to affect responsiveness to some sweeteners do not influence responsiveness to Polycose in mice (Inoue et al., 2007). Furthermore, mice lacking T1R3 show only slightly reduced preferences for Polycose over water in a $60 \mathrm{~s}$ two-bottle preference test and display concentration-dependent behavior across test sessions emulating that seen in WT mice (Zukerman et al., 2009a). Similarly, responses to Polycose in a brief-access test are comparable between WT controls and T1R3 KO as well as T1R2 KO mice (Treesukosol et al., 2009). In contrast, unconditioned responses to Na-saccharin and sucrose in the same $\mathrm{KO}$ mice are severely reduced or abolished (Treesukosol et al., 2009; Zukerman et al., 2009a). Moreover, although the chorda tympani nerve in T1R3 KO mice is relatively unresponsive to a range of sucrose concentrations, its response to Polycose is similar to that observed in WT mice (Zukerman et al., 2009a).

Although these findings suggest the T1R2 and T1R3 proteins are individually unnecessary for relatively normal Polycosestimulated taste function, it remains possible that either subunit alone is sufficient to maintain normal responsiveness to glucose polymer mixtures. Indeed, some degree of responsiveness to sweeteners, albeit severely blunted, has been observed in T1R2 and T1R3 KO mice, which disappears when both subunits are deleted (Zhao et al., 2003). Moreover, Polycose consists of glucose polymers of various chain lengths (Kennedy et al., 1995), provoking the question as to what the relationship is between glucose polymer chain length and taste-related behavioral responses in these KO preparations. Therefore, we presented sepa- 
rate groups of T1R2 $\mathrm{KO}$ and T1R3 $\mathrm{KO}$ mice and their WT littermate controls with glucose, maltose, maltotriose, and Polycose and assessed concentration-dependent licking responses of these animals in a brief-access taste test. Importantly, we also tested the responses of mice lacking both T1R2 and T1R3 to decisively address whether the presence of at least one subunit of the T1R2 +3 heterodimer is necessary for the maintenance of normal taste-related responsiveness to glucose polymers and potentially provide strong behavioral evidence for the presence of a glucose polymer taste receptor that is independent of T1R2 and T1R3.

\section{Materials and Methods}

Subjects. Male and female breeding pairs of mice that were homozygous null for the Tas1 2 or Tas1r3 gene (initially derived from 129X1/ SvJ and backcrossed for at least three generations with C57BL/ 6 mice) were provided by Dr. Charles Zuker (University of California, San Diego, La Jolla, CA). Homozygous null mice and wild-type C57BL/6J (B6) mice (Jackson Laboratory) were paired to generate mice that were heterozygous $(-/+)$ for Tas1r2 or Tas1r3. These mice were in turn paired to generate heterozygous $(-/+)$, homozygous null $(-/-)$, and wild-type $(+/+)$ mice. From these mice, homozygous null and wild-type samesex littermate controls served as subjects in the behavioral tests.

Mice that were homozygous null for Tas1r2 or Tas1r3 were paired, resulting in mice heterozygous for Tas1r2 and Tas1r3. These mice were in turn paired to generate mice heterozygous $(-1+)$, homozygous null $(-/-)$, and wild-type $(+/+)$ for Tas1r2 and/or Tas1r3. Mice that were homozygous null for both Tas $1 \mathrm{r} 2$ and Tas $1 r 3$ were paired to generate more animals homozygous null for both genes. These animals were assigned as subjects in the behavioral tests (Table 1)

The mice were housed in polycarbonate shoebox cages in a room where humidity, temperature, and a $12 \mathrm{~h}-12 \mathrm{~h}$ light-dark lighting cycle were automatically controlled. Mice were provided ad libitum chow (Purina Laboratory Chow 5001) and deionized reverse-osmosis water, except where noted.

Behavioral tests began when mice were at least 7 weeks of age. These animals were singly housed with unrestricted access to food and water for at least $2 \mathrm{~d}$ before the start of behavioral testing. For the $4 \mathrm{~d}$ of water training, the mice were placed on a restricted water-access schedule for which water was available only during the daily testing sessions. Water bottles were removed on Sunday, no more than $23 \mathrm{~h}$ before testing. Mice that weighed $<85 \%$ of their free-drinking weight during the water-restriction schedule received $1 \mathrm{ml}$ of supplemental water $1 \mathrm{~h}$ after the end of the testing session. Mice that dropped below $85 \%$ of their free-drinking body weight for 2 consecutive days received $2 \mathrm{ml}$ of supplemental water $1 \mathrm{~h}$ after the end of the testing session. Water bottles were returned to their home cages after the last water training session.

Taste stimuli. All solutions were prepared with deionized reverseosmosis water and presented at room temperature. Test stimuli consisted of six concentrations of glucose $(0.0625,0.125,0.25,0.5,1.0$, $2.0 \mathrm{M}$; BDH Chemicals), maltose (two glucose moieties-0.03125, $0.0625,0.125,0.25,0.5$, and $1.0 \mathrm{M}$; Alfa Aesar), maltotriose (three glucose moieties- $0.01875,0.0375,0.75,0.15,0.3$, and $0.6 \mathrm{M}$; Sigma), Polycose $(1,2,8,16,24$, and 32\%; Ross Laboratories) and Na-
Table 1. Number of mice and male (M) and female (F) composition in each group for trial analysis

\begin{tabular}{|c|c|c|c|c|c|c|c|c|c|c|c|c|}
\hline & \multicolumn{3}{|c|}{ Glucose } & \multicolumn{3}{|c|}{ Maltose } & \multicolumn{3}{|c|}{ Maltotriose } & \multicolumn{3}{|c|}{ Polycose } \\
\hline & $n$ & M & $\mathrm{F}$ & $n$ & M & $\mathrm{F}$ & $n$ & M & $\mathrm{F}$ & $n$ & M & $\mathrm{F}$ \\
\hline \multicolumn{13}{|l|}{ T1R2 } \\
\hline KO & 8 & 6 & 2 & 9 & 3 & 6 & 8 & 3 & 5 & 11 & 7 & 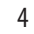 \\
\hline WT & 8 & 6 & 2 & 9 & 3 & 6 & 8 & 3 & 5 & 11 & 7 & \\
\hline \multicolumn{13}{|l|}{ T1R3 } \\
\hline KO & 9 & 5 & 4 & 9 & 4 & 5 & 7 & 3 & 4 & 6 & 4 & \\
\hline WT & 9 & 5 & 4 & 9 & 4 & 5 & 7 & 3 & 4 & 6 & 4 & \\
\hline \multicolumn{13}{|l|}{$\mathrm{T} 1 \mathrm{R} 2 / 3$} \\
\hline KO & 10 & 5 & 5 & 10 & 5 & 5 & 10 & 5 & 5 & 10 & 5 & \\
\hline WT & 17 & 11 & 6 & 18 & 7 & 11 & 15 & 6 & 9 & 17 & 11 & \\
\hline
\end{tabular}

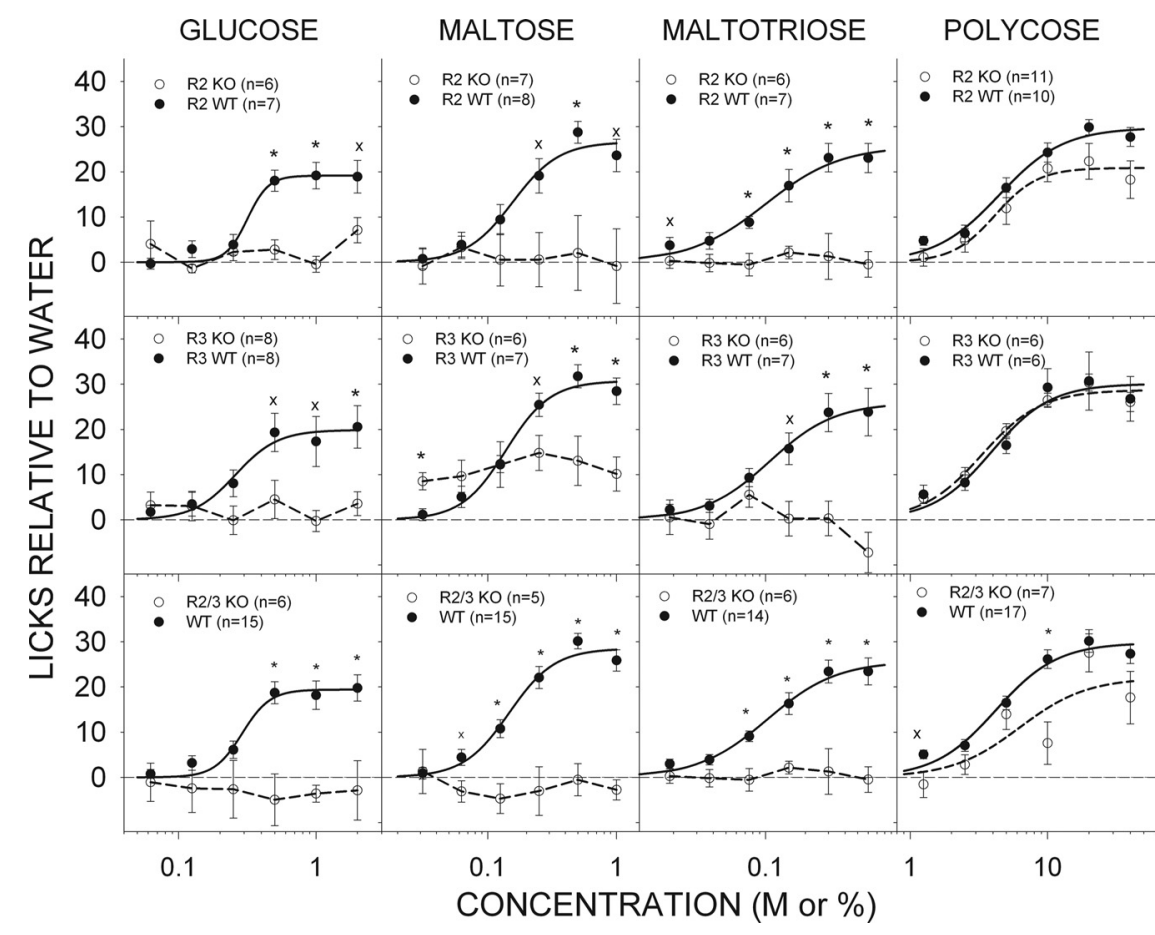

Figure 1. Mean ( \pm SE) licks to glucose, maltose, maltotriose, and Polycose adjusted for licks to water for T1R2 WT (top panel, filled circles), T1R2 K0 (top panel, open circles), T1R3 WT (middle panel, filled circles), T1R3 KO (middle panel, open circles), WT (bottom panel, filled circles), and T1R2/3 KO (bottom panel, open circles) mice during the first session. Only $\mathrm{T} 1 \mathrm{R} 2 \mathrm{KO}$, T1R3 KO, or T1R2/3 K0 mice for glucose, maltose, or maltotriose. *Performance that was significantly differen $(p \leq 0.05)$ between $\mathrm{KO}$ and WT groups as revealed by Bonferroni-corrected post hoc $t$ tests, ${ }^{\mathrm{x}}$ statistical significance that did not survive Bonferroni correction.

saccharin $(0.1,0.5,1.0,5.0,10.0$, and $50.0 \mathrm{~mm}$; Sigma). These concentrations span the dynamic range of responsiveness for mice, and concentrations within this range have been used in previous behavioral and electrophysiological studies (e.g., Eylam and Spector, 2004; Dotson et al., 2005; Glendinning et al., 2005; Inoue et al., 2007; Treesukosol et al., 2009; Zukerman et al., 2009a). These ranges also overlap each other in regards to mass volume percentages.

Procedure. Testing took place in a lickometer (Davis MS-160, DiLog Instruments) as described previously (e.g., Smith, 2001; Glendinning et al., 2002). A mouse was placed in the test chamber of the apparatus. A motorized shutter opened allowing the mouse access to a single spout, positioned $\sim 5 \mathrm{~mm}$ behind a slot, which was connected to a glass tube containing a taste stimulus. To minimize potential olfactory cues from the stimulus, a small fan positioned above the sample slot directed a current of air past the drinking spout. The mouse initiated a trial by licking the spout. Each trial was $5 \mathrm{~s}$, followed by closure of the shutter and a $7.5 \mathrm{~s}$ intertrial interval during which time the tube was changed via a motorized block and the shutter reopened for the next trial. The first test 
Table 2. ANOVA values for tests of Licks Relative to Water values as a function of genotype and concentration for test session 1

\begin{tabular}{|c|c|c|c|c|}
\hline & Glucose & Maltose & Maltotriose & Polycose \\
\hline \multicolumn{5}{|l|}{ T1R2 } \\
\hline Genotype & $\begin{array}{c}F_{(1,11)}=19.426 \\
p=0.001\end{array}$ & $\begin{array}{c}F_{(1,13)}=5.882 \\
p=0.031\end{array}$ & $\begin{array}{c}F_{(1,11)}=20.167 \\
p=0.001\end{array}$ & $\begin{array}{c}F_{(1,19)}=2.558 \\
p=0.126\end{array}$ \\
\hline Concentration & $\begin{array}{c}F_{(5,55)}=8.419 \\
p<0.001\end{array}$ & $\begin{array}{c}F_{(5,65)}=8.401 \\
p<0.001\end{array}$ & $\begin{array}{c}F_{(5,55)}=10.634 \\
p<0.001\end{array}$ & $\begin{array}{c}F_{(5,95)}=62.128 \\
p<0.001\end{array}$ \\
\hline Genotype $\times$ Concentration & $\begin{array}{c}F_{(5,55)}=6.538 \\
p<0.001\end{array}$ & $\begin{array}{c}F_{(5,65)}=8.457 \\
p<0.001\end{array}$ & $\begin{array}{c}F_{(5,55)}=8.336 \\
p<0.001\end{array}$ & $\begin{array}{c}F_{(5,95)}=1.388 \\
p=0.236\end{array}$ \\
\hline \multicolumn{5}{|l|}{ T1R3 } \\
\hline Genotype & $\begin{array}{c}F_{(1,14)}=8.256 \\
p=0.012\end{array}$ & $\begin{array}{c}F_{(1,11)}=2.498 \\
p=0.142\end{array}$ & $\begin{array}{c}F_{(1,11)}=12.802 \\
p<0.001\end{array}$ & $\begin{array}{c}F_{(1,10)}<0.001 \\
p=0.999\end{array}$ \\
\hline Concentration & $\begin{array}{c}F_{(5,70)}=4.625 \\
p=0.001\end{array}$ & $\begin{array}{c}F_{(5,55)}=27.826 \\
p<0.001\end{array}$ & $\begin{array}{c}F_{(5,55)}=5.714 \\
p<0.001\end{array}$ & $\begin{array}{c}F_{(5,50)}=37.605 \\
p<0.001\end{array}$ \\
\hline Genotype $\times$ Concentration & $\begin{array}{c}F_{(5,70)}=4.283 \\
p=0.002\end{array}$ & $\begin{array}{c}F_{(5,55)}=17.220 \\
p<0.001\end{array}$ & $\begin{array}{c}F_{(5,55)}=11.372 \\
p<0.001\end{array}$ & $\begin{array}{c}F_{(5,50)}=0.362 \\
p=0.872\end{array}$ \\
\hline \multicolumn{5}{|l|}{$\mathrm{T} 1 \mathrm{R} 2 / 3$} \\
\hline Genotype & $\begin{array}{c}F_{(1,19)}=19.024 \\
p<0.001\end{array}$ & $\begin{array}{c}F_{(1,18)}=29.711 \\
p<0.001\end{array}$ & $\begin{array}{c}F_{(1,18)}=22.204 \\
p<0.001\end{array}$ & $\begin{array}{c}F_{(1,21)}=7.408 \\
p=0.013\end{array}$ \\
\hline Concentration & $\begin{array}{c}F_{(5,95)}=3.724 \\
p=0.004\end{array}$ & $\begin{array}{c}F_{(5,90)}=21.572 \\
p<0.001\end{array}$ & $\begin{array}{c}F_{(5,90)}=13.342 \\
p<0.001\end{array}$ & $\begin{array}{c}F_{(5,105)}=48.874 \\
p<0.001\end{array}$ \\
\hline Genotype $\times$ Concentration & $\begin{array}{c}F_{(5,95)}=5.938 \\
p<0.001\end{array}$ & $\begin{array}{c}F_{(5,90)}=23.547 \\
p<0.001\end{array}$ & $\begin{array}{c}F_{(5,90)}=11.498 \\
p<0.001\end{array}$ & $\begin{array}{c}F_{(5,105)}=4.326 \\
p=0.001\end{array}$ \\
\hline
\end{tabular}

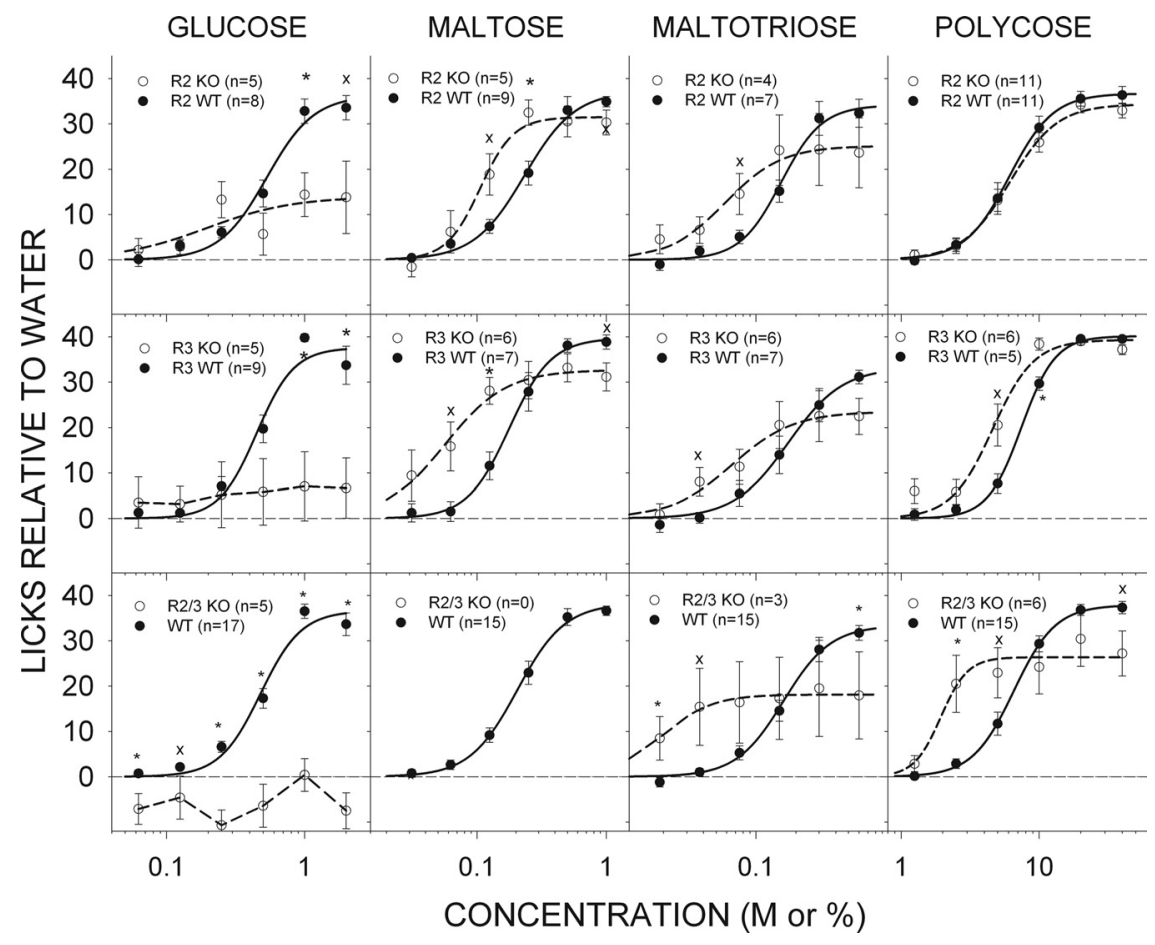

Figure 2. Mean ( \pm SE) to glucose, maltose, maltotriose, and Polycose adjusted for licks to water for T1R2 WT (top panel, filled circles), T1R2 KO (top panel, open circles), T1R3 WT (middle panel, filled circles), T1R3 KO (middle panel, open circles), WT (bottom panel, filled circles), and T1R2/3 KO (bottom panel, open circles) mice during the third session. Only mice that initiated at least one trial per concentration were included in this analysis. Curves could not be fit to the data for T1R3 $\mathrm{K} 0$ or T1R2/3 K0 mice to glucose. No T1R2/3 K0 mice initiated at least one trial per maltose concentration, and thus data were not included for T1R2/3 K0 mice for maltose. *Performance that was significantly different $(p \leq 0.05)$ between $\mathrm{K} 0$ and WT groups as revealed by Bonferroni-corrected post hoc t tests, ${ }^{{ }}$statistical significance that did not survive Bonferroni correction.

stimulus for each session was the highest concentration of the compound, after which concentrations were presented in randomized order (without replacement) in blocks of trials. The mice were able to initiate as many trials as possible during the daily 25 min sessions.

Water training. The mice were placed on a $23 \mathrm{~h}$ restricted water-access schedule during the $4 \mathrm{~d}$ of water training. On days 1 and 2 , the mice were presented with a single stationary tube of water and trained to lick in the apparatus. The 25 min session began when the mouse licked the spout.
On days 3 and 4, seven sipper tubes of water were presented, one at a time, in $5 \mathrm{~s}$ trials over the 25 min session.

Stimulus testing. During this phase, a given taste stimulus was tested for a 25 min session on Monday, Wednesday, and Friday. Mice were assigned to one of four stimulus groups so that each KO and WT littermate pair was assigned to the same group. Mice were presented glucose, maltose, maltotriose, or Polycose as their first taste stimulus. The following week, all mice were presented a range of Polycose concentrations. In the last week of testing, all groups were tested with $\mathrm{Na}$-saccharin.

To promote stimulus sampling, we maintained the mice on a partial food and water restriction schedule by presenting them with $\sim 1 \mathrm{~g}$ of chow and $\sim 2 \mathrm{ml}$ of water $\sim 23 \mathrm{~h}$ before testing (see Glendinning et al., 2002). The order of testing of different genotypes was balanced as much as possible throughout the day. Recovery days during which food and water were available ad libitum were interjected between testing days. Due to the large sample sizes, animals were tested in phases with representations from both T1R2 and T1R3 groups in each phase. The last phase tested all the T1R $2 / 3$ KO mice.

Data analysis. For test stimuli (week 2), the mean number of licks at each concentration was calculated by collapsing all trials across a single session. For control Polycose testing (week 3) and control Na-saccharin testing (week 4), the mean number of licks at each concentration was calculated by collapsing all trials across the three test sessions. The mean number of licks to water was subtracted from the mean number of licks at each concentration, yielding a Licks Relative to Water value. This measure was successfully used in previous studies (Spector et al., 1996; Jiang et al., 2008; Treesukosol et al., 2009) to produce concentration-response curves that are adjusted to a water baseline. The Licks Relative to Water value for each concentration of a stimulus was compared using ANOVAs. The statistical rejection criterion of 0.05 was used for all analyses. 
Table 3. ANOVA values for tests of Licks Relative to Water values as a function of genotype and concentration for test session 3

\begin{tabular}{|c|c|c|c|c|}
\hline & Glucose & Maltose & Maltotriose & Polycose \\
\hline \multicolumn{5}{|l|}{ T1R2 } \\
\hline Genotype & $\begin{array}{c}F_{(1,11)}=5.124 \\
p=0.045\end{array}$ & $\begin{array}{c}F_{(1,12)}=1.376 \\
p=0.263\end{array}$ & $\begin{array}{c}F_{(1,9)}=0.229 \\
p=0.644\end{array}$ & $\begin{array}{c}F_{(1,20)}=0.438 \\
p=0.516\end{array}$ \\
\hline Concentration & $\begin{array}{c}F_{(5,55)}=24.438 \\
p<0.001\end{array}$ & $\begin{array}{c}F_{(5,60)}=112.836 \\
p<0.001\end{array}$ & $\begin{array}{c}F_{(5,45)}=48.782 \\
p<0.001\end{array}$ & $\begin{array}{c}F_{(5,100)}=178.154 \\
p<0.001\end{array}$ \\
\hline Genotype $\times$ Concentration & $\begin{array}{c}F_{(5,55)}=7.961 \\
p<0.001\end{array}$ & $\begin{array}{c}F_{(5,60)}=8.17 \\
p<0.001\end{array}$ & $\begin{array}{c}F_{(5,45)}=5.777 \\
p<0.001\end{array}$ & $\begin{array}{c}F_{(5,100)}=0.621 \\
p=0.684\end{array}$ \\
\hline \multicolumn{5}{|l|}{ T1R3 } \\
\hline Genotype & $\begin{array}{c}F_{(1,12)}=6.447 \\
p=0.026\end{array}$ & $\begin{array}{c}F_{(1,11)}=2.634 \\
p=0.133\end{array}$ & $\begin{array}{c}F_{(1,11)}=0.255 \\
p=0.624\end{array}$ & $\begin{array}{c}F_{(1,9)}=5.887 \\
p=0.038\end{array}$ \\
\hline Concentration & $\begin{array}{c}F_{(5,60)}=27.340 \\
p<0.001\end{array}$ & $\begin{array}{c}F_{(5,55)}=40.956 \\
p<0.001\end{array}$ & $\begin{array}{c}F_{(5,55)}=42.739 \\
p<0.001\end{array}$ & $\begin{array}{c}F_{(5,45)}=164.077 \\
p<0.001\end{array}$ \\
\hline Genotype $\times$ Concentration & $\begin{array}{c}F_{(5,60)}=19.035 \\
p<0.001\end{array}$ & $\begin{array}{c}F_{(5,55)}=5.853 \\
p<0.001\end{array}$ & $\begin{array}{c}F_{(5,55)}=3.646 \\
p<0.001\end{array}$ & $\begin{array}{c}F_{(5,45)}=4.560 \\
p=0.002\end{array}$ \\
\hline \multicolumn{5}{|l|}{$\mathrm{T} 1 \mathrm{R} 2 / 3$} \\
\hline Genotype & $\begin{array}{c}F_{(1,20)}=93.644 \\
p<0.001\end{array}$ & - & $\begin{array}{c}F_{(1,16)}=0.065 \\
p=0.802\end{array}$ & $\begin{array}{c}F_{(1,20)}=0.253 \\
p=0.620\end{array}$ \\
\hline Concentration & $\begin{array}{c}F_{(5,100)} 32.815 \\
p<0.001\end{array}$ & - & $\begin{array}{c}F_{(5,80)}=35.590 \\
p<0.001\end{array}$ & $\begin{array}{c}F_{(5,100)}=96.541 \\
p<0.001\end{array}$ \\
\hline Genotype $\times$ Concentration & $\begin{array}{c}F_{(5,100)}=20.909 \\
p<0.001\end{array}$ & - & $\begin{array}{c}F_{(5,80)}=21.149 \\
p<0.001\end{array}$ & $\begin{array}{c}F_{(5,100)}=18.050 \\
p<0.001\end{array}$ \\
\hline
\end{tabular}

Curves were fit to mean data for each group by using the following logistic function:

$$
f(x)=\frac{a}{\left(1+10^{(x-c) b}\right)},
$$

where $x=\log _{10}$ stimulus concentration, $a=$ asymptotic lick response adjusted for water, $b=$ slope, and $c=\log _{10}$ concentration at the inflection point.

All mice were included in the analysis of the number of trials initiated to each of the stimuli. However, Licks Relative to Water values for a particular stimulus from an individual mouse were included for analysis only if the mouse initiated at least one trial from each concentration during the analyzed session for test stimuli (week 2) or at least two trials from each concentration across the three sessions for the control Polycose and Na-saccharin (weeks 3 and 4). This criterion was in place to be certain that we had an adequate representation of the responses to the entire stimulus set. Two-way ANOVAs (genotype $\times$ concentration) were conducted to compare responses of each $\mathrm{KO}$ group with its respective WT control group. Bonferroni-corrected post hoc $t$ tests were conducted at each concentration to compare licking responses between the genotypes. Data from T1R2 KO and T1R3 KO mice were compared with those of their respective WT control groups. Data from T1R2/3 KO mice were compared with those from T1R2 WT and T1R3 WT groups combined (WT).

Genotyping. Tail samples were obtained from mice to determine genotype by PCR. DNA was extracted and PCR was performed in a final reaction mixture volume of $12.5 \mu \mathrm{l}$ including $1 \mu \mathrm{l}$ of the isolated DNA.

The primers used for T1R2 were 5' -TTG GAG GAG GGG GCA GTG GGA GTG-3' and 5' ${ }^{\prime}$-ATA ATC CTC TCC TGC CAC CCT AAC- $3^{\prime}$ and 5' -CTG CCC CAA AGG CCT ACC CGC TTC-3'. PCR conditions were as follows: a preheating step for $30 \mathrm{~s}$ at $95^{\circ} \mathrm{C}$ followed by 42 cycles of $30 \mathrm{~s}$ at $95^{\circ} \mathrm{C}, 15 \mathrm{~min}$ at $60^{\circ} \mathrm{C}$, and $1 \mathrm{~min}$ at $72^{\circ} \mathrm{C}$ and an autoextension step of $10 \mathrm{~min}$ at $72^{\circ} \mathrm{C}$.

For T1R3, the primers used were $5^{\prime}$-CCC CAC ACA CCC ATC TAT TGT TAG- $3^{\prime}$ and $5^{\prime}$-GAC TTG AAT GCT TCT GCC CCC TAG- ${ }^{\prime}$ ' PCR conditions were as follows: a preheating step for $30 \mathrm{~s}$ at $95^{\circ} \mathrm{C}$ followed by 40 cycles of $30 \mathrm{~s}$ at $95^{\circ} \mathrm{C}, 15 \mathrm{~min}$ at $50^{\circ} \mathrm{C}$, and $2.5 \mathrm{~min}$ at $72^{\circ} \mathrm{C}$ and an autoextension step of $10 \mathrm{~min}$ at $72^{\circ} \mathrm{C}$.

The PCR products were separated using electrophoresis on a $1 \%$ agarose gel.

\section{Results}

\section{Glucose}

Across the three sessions during which glucose was presented, T1R2 KO, T1R3 KO, and T1R2/3 double KO mice displayed virtually flat concentration-response functions, compared with the WT controls as evident in the first (Fig. 1, Table 2) and third (Fig. 2, Table 3) sessions.

All three $\mathrm{KO}$ genotypes [T1R2 $\mathrm{KO}\left(t_{(14)}=-2.596 ; p=0.021\right)$, $\mathrm{T} 1 \mathrm{R} 3 \mathrm{KO}\left(t_{(16)}=-3.595 ; p=0.002\right)$, and T1R2/3 KO $\left(t_{(25)}=\right.$ $-8.980 ; p<0.001)$ ] initiated significantly fewer trials of glucose collapsed across the three test sessions than did their WT controls (Fig. 3).

\section{Maltose}

On the first session during which maltose was presented, T1R2 WT and T1R3 WT mice responded in a concentrationdependent manner, whereas, as was observed with glucose, the T1R2 KO, T1R3 KO, and T1R2/3 KO groups displayed essentially flat concentration-response functions (Fig. 1, Table 2). By the third session in which maltose was presented, however, one-way ANOVAs did reveal a significant effect of concentration on licking in both the T1R2 $\mathrm{KO}\left(F_{(5,20)}=39.2, p<0.001\right)$ and T1R3 KO $\left(F_{(5,25)}=9.3, p<0.001\right)$ groups, supporting what is evident from the curves: the KO mice that initiated at least one trial per concentration during a session displayed concentration-dependent licking responses on session 3 , in contrast to what was observed on session 1. Two-way ANOVAs of Licks Relative to Water values also revealed a genotype $\times$ concentration effect when responses of T1R2 KO and T1R3 KO mice were compared with their respective WT control groups (Table 3 ). It is apparent from the curves that this is largely attributable to the $\mathrm{KO}$ mice licking more than their WT counterparts, to some low/mid-range maltose concentrations (Fig. 2).

In contrast to the single $\mathrm{KO}$ groups, the T1R2/3 double $\mathrm{KO}$ mice displayed virtually no concentration-dependent licking responses to maltose across the three sessions (Figs. 1, 2). In fact, during the third session, none of the $10 \mathrm{~T} 1 \mathrm{R} 2 / 3 \mathrm{KO}$ mice tested initiated at least one trial per concentration; thus, no T1R2/3 KO 


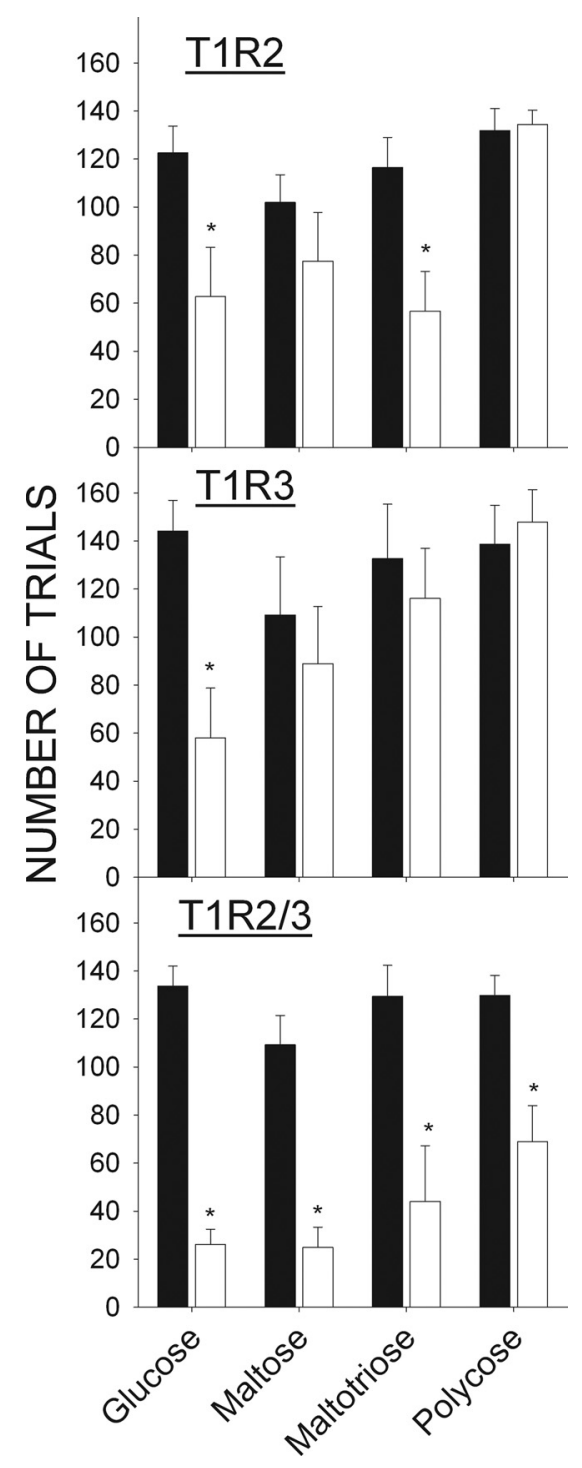

Figure 3. Mean ( $\pm \mathrm{SE})$ number of trials collapsed across three sessions, initiated to glucose, maltose, maltotriose, and Polycose for T1R2 WT (top panel, black bars), T1R2 K0 (top panel, white bars), T1R3 WT (middle panel, black bars), T1R3 K0 (middle panel, white bars), WT (bottom panel, black bars), and T1R2/3 KO (bottom panel, white bars) mice. The K0 groups that initiated significantly $(p \leq 0.05)$ fewer trials than their WT counterparts are denoted by *.

data from this session were included for the analysis of Licks Relative to Water values.

The number of trials initiated to maltose collapsed across the three test sessions did not significantly differ between the T1R2 $\mathrm{KO}$ and their WT controls $\left(t_{(16)}=-1.204 ; p=0.246\right)$, nor did it differ between the T1R3 $\mathrm{KO}$ and their WT controls $\left(t_{(16)}=\right.$ $-0.613 ; p=0.548)$. However, T1R2/3 KO mice initiated significantly fewer trials to maltose than did the WT mice $\left(t_{(25)}=\right.$ $-4.889 ; p<0.001$ ) (Fig. 3).

\section{Maltotriose}

Both T1R2 WT and T1R3 WT mice displayed concentrationdependent licking responses on the first session to maltotriose, whereas all three $\mathrm{KO}$ groups had flat concentration-response functions (Fig. 1, Table 2). However, both the T1R2 $\mathrm{KO}\left(F_{(5,15)}=\right.$ 8.2, $p=0.001)$ and the $\operatorname{TrR} 3 \mathrm{KO}\left(F_{(5,25)}=10.3, p<0.001\right)$ groups had significant increases in Licks Relative to Water as a function of maltotriose concentration by the third session (Fig. 2, Table
3). Although it did appear that by the third session, a small subset of the T1R2/3 KO mice showed some degree of concentrationdependent licking, this failed to reach significance.

Similar to what was observed in the maltose group, two-way ANOVAs of Licks Relative to Water values revealed a genotype $\times$ concentration effect when responses of T1R2 KO, T1R3 KO, and T1R2/3 KO mice were compared with their WT counterparts for sessions 1 and 3 (Table 3 ). For session 1, it is clear that the interaction is due to all three $\mathrm{KO}$ groups licking midrange to high concentrations of maltotriose less than the WT mice. This was also the case for the T1R2/3 KO mice in session 3. The significant genotype $\times$ concentration interaction for the T1R2 KO and the T1R3 KO mice in session 3 was likely due to the KO mice licking more than their WT controls to some midrange maltotriose concentrations and slightly less to high concentrations.

The T1R2 KO $\left(t_{(14)}=-2.763 ; p=0.015\right)$ and the T1R2/3 KO $\left(t_{(23)}=-3.462 ; p=0.002\right)$ groups initiated significantly fewer trials to maltotriose collapsed across sessions than their WT controls. The number of trials initiated to maltotriose did not differ between T1R3 KO mice and their WT counterparts $\left(t_{(12)}=\right.$ $-0.671 ; p=0.515$ ) (Fig. 3).

\section{Polycose}

The responses of the KO groups to Polycose were notably different from that seen for glucose, maltose, and maltotriose in a very important way; on the very first session all $\mathrm{KO}$ groups, including the T1R2/3 KO, increased their lick rate as a function of concentration (Fig. 1, Table 2). The T1R2/3 KO group did, however, lick less than the combined WT group, especially at the $10 \%$ concentration, which accounted for a significant genotype effect and a significant genotype $\times$ concentration interaction. In session 3 , a genotype effect and a significant genotype $\times$ concentration interaction appeared for the analyses involving the T1R3 single KOs compared with their WT controls, but this was because the KO mice actually licked some of the concentrations at rates higher than the WT mice (Fig. 2). Also in session 3, there was a significant genotype $\times$ concentration interaction for the Licks Relative to Water values comparing the T1R2/3 KO mice with the combined WT group which is evident from the crossover nature of the curves (Table 3).

In regard to the number of trials initiated to Polycose collapsed across sessions, T1R2 $\mathrm{KO}\left(t_{(20)}=0.509 ; p=0.617\right)$ and T1R3 KO mice $\left(t_{(10)}=0.168 ; p=0.870\right)$ did not significantly differ from their respective WT control groups. In contrast, T1R2/3 KO mice initiated fewer trials to Polycose compared with WT mice $\left(t_{(25)}=-3.816 ; p=0.001\right)$ (Fig. 3). Thus, while it is clear that the T1R2/3 KO mice clearly responded to Polycose in a concentration-dependent manner, the combined absence of both T1R2 and T1R3 appeared to attenuate the degree of Polycose responsiveness when all of the data are considered on the whole.

\section{Control sessions}

It has been previously been shown that T1R2 KO and T1R3 KO mice display concentration-dependent responsiveness to Polycose, similar to that of WT mice, in brief-access and $60 \mathrm{~s}$ preference tests (Treesukosol et al., 2009; Zukerman et al., 2009a). Accordingly, in the present study, Polycose was presented to confirm a lack of effect from the deletion of the respective genes. As predicted, even on the very first control session, regardless of the previous test session T1R2 KO, T1R3 KO, and T1R2/3 KO groups displayed concentration-dependent licking responses to Polycose that were similar to WT controls (data not shown). Thus, the 
data across the three control sessions were collapsed for analysis (Fig. 4). Clearly, all of the KO genotypes showed concentration-dependent unconditioned licking to Polycose. Similar as to what was observed during Polycose test sessions (i.e., week 2), the T1R $2 / 3 \mathrm{KO}$ mice did lick less than the WT group, resulting in a significant genotype effect and a significant genotype $\times$ concentration interaction. The T1R2 KO and T1R3 KO mice licked more vigorously than their WT controls to the midrange concentrations, which accounted for significant genotype $\times$ concentration interactions, as well as a main effect of genotype for the T1R3 comparison (Table 3 ).

As shown in Figure 4, T1R2 $\mathrm{KO}\left(t_{(72)}=\right.$ $0.600 ; p=0.550)$ and T1R3 KO $\left(t_{(60)}=\right.$ $1.474 ; p=0.146)$ mice did not significantly differ in the number of trials initiated during control Polycose sessions compared with their WT controls, but T1R2/3 KO mice initiated significantly fewer trials than WT mice $\left(t_{(106)}=-2.117 ; p=0.037\right)$.

$\mathrm{Na}$-saccharin control sessions served as a functional confirmation of the $\mathrm{KO}$ status of the mice. Consistent with what has been previously observed (Zhao et al., 2003; Treesukosol et al., 2009), in this experiment, T1R2 KO, T1R3 KO, and T1R2/3 KO mice showed virtually no responsiveness to a range of Na-saccharin concentrations, whereas the WT groups displayed concentration-dependent responses (Fig. 4, Table 4). Although repeatedmeasures one-way ANOVAs did reveal a significant effect of concentration on licking for T1R2 KO mice $\left(F_{(5,145)}=4.690, p=0.001\right)$ and T1R3 KO mice $\left(F_{(5,160)}=2.511\right.$, $p=0.032$ ) but not T1R2/3 KO mice, as is evident from the curves and two-way ANOVA statistics, all KO groups showed severely reduced licking responses to Na-saccharin. In fact, the mean Licks Relative to Water values for T1R3 KO mice are not greater than 0 for any of the Na-saccharin concentrations presented.

The T1R2 KO $\left(t_{(72)}=-3.616 ; p=0.001\right), \operatorname{T1R} 3 \mathrm{KO}\left(t_{(70)}=\right.$ $-4.941 ; p<0.001)$, and T1R2/3 KO $\left(t_{(111)}=-7.177 ; p<0.001\right)$ groups all initiated significantly fewer trials to Na-saccharin compared with WT mice (Fig. 4).

\section{Discussion}

The findings of the present study provide compelling behavioral evidence for the presence of a glucose polymer taste receptor that is independent of the $\mathrm{T} 1 \mathrm{R} 2+3$ heterodimer. On the first test session, T1R2 KO, T1R3 KO, and T1R2/3 double KO groups all failed to show concentration-dependent responses to glucose, maltose, or maltotriose. In striking contrast, a concentrationdependent licking response to Polycose was observed on the first test session for all of the $\mathrm{KO}$ groups. These findings demonstrate that concentration-linked unconditioned affective responsiveness to Polycose does not depend on the combined presence of both proteins, or on the individual presence of T1R2 or T1R3. Further, these data significantly buttress the longstanding hypothesis championed by Sclafani (e.g., 1987, 2004b) that rodents and perhaps other species possess a novel taste receptor(s) that binds with maltooligosaccharides.

In the subsequent sessions, a concentration-dependent licking response for maltose and maltotriose emerged in some T1R2 $\mathrm{KO}$ and T1R3 KO mice. Apparently maltose and maltotriose provide a sensory signal(s) that is too weak to elicit unconditioned licking on the first session, but after it is associated with postingestive feedback is sufficiently salient to promote concentration-dependent licking in T1R2 and T1R3 KO mice. Such a cue might be simply too weak or not present in glucose solutions to support the formation of such associations in the $\mathrm{KO}$ mice. Zukerman et al. (2009b) have shown that increases in sucrose preference in T1R3 KO mice as a function of prior testing experience depends, in part, on an intact olfactory system. However, in our study, the fact that the experience-dependent increase in responsiveness to maltose and maltotriose was observed in single $\mathrm{KO}$ mice but only weakly if at all for T1R2/3 KO mice suggests that this signal is of a taste origin. In the literature, there are other examples in which $\mathrm{KO}$ mice, initially ageusic as a result of various taste-related gene deletions, display increased behavioral responsiveness to saccharides after previous exposure to caloric compounds (Zhao et al., 2003; Sclafani, 2007; Treesukosol et al., 2009). This has been attributed to a learned association between an orosensory cue(s) and the post-ingestive nutrient feedback from saccharide exposure. Indeed, the pairing of a novel noncaloric solution with an intragastric infusion of a caloric solution 
Table 4. ANOVA values for tests of Licks Relative to Water values as a function of genotype and concentration for the control sessions to Polycose and Na-saccharin

\begin{tabular}{|c|c|c|c|c|c|c|}
\hline & \multicolumn{3}{|l|}{ Polycose } & \multicolumn{3}{|l|}{$\mathrm{Na}-$ Saccharin } \\
\hline & Genotype & Concentration & Genotype $\times$ Concentration & Genotype & Concentration & Genotype $\times$ Concentration \\
\hline T1R2 & $\begin{array}{c}F_{(1,68)}=0.400 \\
p=0.529\end{array}$ & $\begin{array}{c}F_{(5,340)}=465.531 \\
p<0.001\end{array}$ & $\begin{array}{c}F_{(5,340)}=8.987 \\
p<0.001\end{array}$ & $\begin{array}{c}F_{(1,65)}=49.880 \\
p<0.001\end{array}$ & $\begin{array}{c}F_{(5,325)}=96.449 \\
p<0.001\end{array}$ & $\begin{array}{c}F_{(5,325)}=42.477 \\
p<0.001\end{array}$ \\
\hline T1R3 & $\begin{array}{c}F_{(1,62)}=11.050 \\
p=0.001\end{array}$ & $\begin{array}{l}F_{(5,310)}=521.185 \\
\quad p<0.001\end{array}$ & $\begin{array}{c}F_{(5,310)}=21.252 \\
p<0.001\end{array}$ & $\begin{array}{c}F_{(1,65)}=90.692 \\
p<0.001\end{array}$ & $\begin{array}{c}F_{(5,325)}=166.485 \\
p<0.001\end{array}$ & $\begin{array}{c}F_{(5,325)}=133.063 \\
p<0.001\end{array}$ \\
\hline $\mathrm{T} 1 \mathrm{R} 2 / 3$ & $\begin{array}{c}F_{(1,95)}=0.076 \\
p=0.783\end{array}$ & $\begin{array}{c}F_{(5,475)}=510.235 \\
p<0.001\end{array}$ & $\begin{array}{c}F_{(5,475)}=26.488 \\
p<0.001\end{array}$ & $\begin{array}{c}F_{(1,98)}=119.124 \\
p<0.001\end{array}$ & $\begin{array}{c}F_{(5,490)}=116.649 \\
p<0.001\end{array}$ & $\begin{array}{c}F_{(5,490)}=129.246 \\
p<0.001\end{array}$ \\
\hline
\end{tabular}

has been shown to elicit a strong preference in rodents (e.g., Mehiel and Bolles, 1984; Elizalde and Sclafani, 1990; Ackroff et al., 1993; Sclafani, 2004a; Sclafani and Glendinning, 2005) including T1R3 KO mice (Sclafani et al., 2010). Importantly, investigators should beware, the brief-access taste test is not entirely immune to the effects of prior testing experience.

In contrast to the responses to maltose and maltotriose, it does not appear that a similar rapid learned association occurred for glucose. This is not surprising considering that T1R2 KO or T1R3 $\mathrm{KO}$ mice were relatively unresponsive to sucrose over three briefaccess test sessions unless they had previous experience to a caloric compound (Polycose), in which case they showed some degree of concentration-dependent licking to sucrose (Treesukosol et al., 2009). Thus, it is plausible that with repeated exposure to glucose, these $\mathrm{KO}$ mice might show increased licking at higher concentrations. Nevertheless, there does appear to be a fundamental difference between the effectiveness of glucose and that of maltose and maltotriose to generate experience-based increases in concentration-dependent licking in a brief-access test. Consistent with these findings, it has been shown that rats prefer maltotriose and maltose to a similar degree. Furthermore, preference for glucose appears to be slightly less than that for maltotriose or maltose (Sclafani et al., 1987), and preference for maltose appears to be less than that for Polycose in rats (Sclafani and Clyne, 1987). In terms of taste quality, maltose appears to be treated as somewhat between the taste qualities of sucrose and Polycose (Nissenbaum and Sclafani, 1987; Spector and Grill, 1988; Sako et al., 1994; Spector et al., 1997; Dotson and Spector, 2007).

Although T1R2 KO, T1R3 KO, and T1R2/3 KO groups all displayed concentration-dependent responses to Polycose, T1R2/3 KO mice initiated significantly fewer trials and also took fewer licks to the higher concentrations of Polycose presented than did WT mice. This was also true for the first Polycose control session in which all of the T1R2/3 KO mice from the different stimulus groups were combined (data not shown). The briefaccess test relies on the hedonic properties of the stimulus to drive a behavioral response, and thus these findings suggest that Polycose has less affective value to $\mathrm{T} 1 \mathrm{R} 2 / 3$ double $\mathrm{KO}$ mice than to mice missing only a single receptor protein. Perhaps the small amounts of small glucose polymers (e.g., glucose, maltose, and maltotriose) contained in Polycose or resulting from salivary amylase activity are capable of stimulating putative T1R2 and T1R3 homodimers. In other words, in T1R2/3 KO mice lacking both the heterodimer and the potential homodimers, the responses to Polycose are not as robust as those observed in the single $\mathrm{KO}$ animals because the signal may be slightly weaker.

It remains possible that maltose and maltotriose may be weakly activating the putative glucose polymer receptor, the optimal stimulus of which appears to have a glucose chain length greater than three (Sclafani et al., 1987). If true, however, the fact that T1R2/3 KO mice did not show significant concentrationdependent licking of these sugars throughout the three test ses- sions suggests that the taste signal generated by the postulated glucose polymer receptor must combine with that provided by either a T1R2 or T1R3 homodimer to provide a sufficient cue to support conditioning. Alternatively, perhaps the T1R2 or T1R3 subunit heteromerizes with another protein to form a functional glucose polymer receptor that is still capable of binding with its adequate stimulus when both $\mathrm{T} 1 \mathrm{R}$ subunits are missing, but in a less effective way. Indeed, these are not mutually exclusive possibilities.

Not only did the KO groups fail to respond to glucose, maltose, or maltotriose in a concentration-dependent manner during the first session, concentration-dependent licking responses to saccharin, as predicted, were abolished in all of the KO groups. These findings support the evidence in the literature that point to the T1R2+3 heterodimer as the principal taste receptor for mediating "sweet" taste and also confirm that the individual presence of the T1R2 or T1R3 subunits cannot maintain behavioral responsiveness to saccharin (Hoon et al., 1999; Bachmanov et al., 2001; Kitagawa et al., 2001; Max et al., 2001; Montmayeur et al., 2001; Nelson et al., 2001; Sainz et al., 2001; Li et al., 2002; Montmayeur and Matsunami, 2002; Xu et al., 2004; Nie et al., 2005).

In summary, it appears that concentration-dependent affective taste responses to Polycose in a brief-access test do not depend on the individual or combined presence of T1R2 and T1R3, and thus these findings provide further support for a novel taste receptor(s) that mediates glucose polymer taste. The evidence suggests that the optimal ligand for stimulating the postulated glucose polymer taste receptor consists of more than three glucose moieties. Finally, responses to Polycose in T1R2/3 KO mice were slightly reduced compared to single $\mathrm{KO}$ mice, and it appears that at least T1R2 or T1R3 is necessary to associate weak orosensory cues of maltose and maltotriose with post-ingestive feedback. These data support the possibility that these subunits can act as homodimers and perhaps are also heteromerizing with another protein to form a fully functional glucose polymer receptor. It has been suggested that the functional role of the putative glucose polymer receptor is to allow animals to detect complex carbohydrates in food sources (Sclafani, 2004b). Bilateral transection of the glossopharyngeal nerve selectively reduces intake of Polycose, but not sucrose in rats (Vigorito et al., 1987), raising the possibility that the yet-to-be-identified glucose polymer receptor is located in the posterior tongue. Furthermore, based on findings from gene deletion studies in mice, it appears that $\alpha$-gustducin and Trpm 5 are necessary taste-signaling intermediaries for unlearned preference of Polycose to be fully expressed (Sclafani et al., 2007). More nerve transection studies incorporating psychophysically oriented tasks and targeted gene deletions would help better localize the oral fields possessing the putative glucose polymer receptor as well as help define its transduction pathway(s). Although longer-chain polysaccharides appear to be comparatively bland to humans and some other species (see Sclafani, 1987), there is evidence to suggest the presence of oral re- 
ceptors that respond to glucose polymers in humans (Chambers et al., 2009). Thus, the signals arising from the putative glucose polymer receptor may not be channeled into neural circuits responsible for taste perception, but rather subserve other physiological functions in humans (see Spector and Glendinning, 2009).

\section{References}

Ackroff K, Manza L, Sclafani A (1993) The rat's preference for sucrose, Polycose and their mixtures. Appetite 21:69-80.

Bachmanov AA, Beauchamp GK (2007) Taste receptor genes. Annu Rev Nutr 27:389-414.

Bachmanov AA, Li X, Reed DR, Ohmen JD, Li S, Chen Z, Tordoff MG, de Jong PJ, Wu C, West DB, Chatterjee A, Ross DA, Beauchamp GK (2001) Positional cloning of the mouse saccharin preference (Sac) locus. Chem Senses 26:925-933.

Chambers ES, Bridge MW, Jones DA (2009) Carbohydrate sensing in the human mouth: effects on exercise performance and brain activity. J Physiol 587:1779-1794.

Chandrashekar J, Hoon MA, Ryba NJP, Zuker CS (2006) The receptors and cells for mammalian taste. Nature 444:288-294.

Dotson CD, Spector AC (2007) Behavioral discrimination between sucrose and other natural sweeteners in mice: implications for the neural coding of T1R ligands. J Neurosci 27:11242-11253.

Dotson CD, Roper SD, Spector AC (2005) PLC $\beta 2$-independent behavioral avoidance of prototypical bitter-tasting ligands. Chem Senses 30:593600.

Elizalde G, Sclafani A (1990) Flavor preferences conditioned by intragastric Polycose infusions: a detailed analysis using an electronic esophagus preparation. Physiol Behav 47:63-77.

Eylam S, Spector AC (2004) Stimulus processing of glycine is dissociable from that of sucrose and glucose based on behaviorally measured taste signal detection in sac 'taster' and 'non-taster' mice. Chem Senses 29:639-649.

Glendinning JI, Gresack J, Spector AC (2002) A high-throughput screening procedure for identifying mice with aberrant taste and oromotor function. Chem Senses 27:461-474.

Glendinning JI, Bloom LD, Onishi M, Zheng KH, Damak S, Margolskee RF, Spector AC (2005) Contribution of alpha-gustducin to taste-guided licking responses of mice. Chem Senses 30:299-316.

Hoon MA, Adler E, Lindemeier J, Battey JF, Ryba NJP, Zuker CS (1999) Putative mammalian taste receptors: a class of taste-specific GPCRs with distinct topographic selectivity. Cell 96:541-551.

Inoue M, Glendinning JI, Theodorides ML, Harkness S, Li X, Bosak N, Beauchamp GK, Bachmanov AA (2007) Allelic variation of the Tas1r3 taste receptor gene selectively affects taste responses to sweeteners: evidence from 129.B6-Tas1r3 congenic mice. Physiol Genomics 32:82-94.

Jiang E, Blonde G, Garcea M, Spector AC (2008) Greater superficial petrosal nerve transection in rats does not change unconditioned licking responses to putatively sweet taste stimuli. Chem Senses 33:709-723.

Kennedy JF, Knill CJ, Taylor DW (1995) Maltodextrins. In: Handbook of starch hydrolysis products and their derivatives (Kearsley MW, Dziedzic SZ, eds.), pp 65-82. London: Blackie Academic and Professional.

Kitagawa M, Kusakabe Y, Miura H, Ninomiya Y, Hino A (2001) Molecular genetic identification of a candidate receptor gene for sweet taste. Biochem Biophys Res Commun 283:236-242.

Li X, Staszewski L, Xu H, Durick K, Zoller M, Adler E (2002) Human receptors for sweet and umami taste. Proc Natl Acad Sci U S A 99:4692-4696.

Max M, Shanker YG, Huang L, Rong M, Liu Z, Campagne F, Weinstein H, Damak S, Margolskee RF (2001) Tas1r3, encoding a new candidate taste receptor, is allelic to the sweet responsiveness locus Sac. Nat Genet 28:58-63.

Mehiel R, Bolles RC (1984) Learned flavor preferences based on caloric outcome. Anim Learn Behav 12:421-427.

Montmayeur J-P, Matsunami H (2002) Receptors for bitter and sweet taste. Curr Opin Neurobiol 12:366-371.

Montmayeur J-P, Liberles SD, Matsunami H, Buck LB (2001) A candidate taste receptor gene near a sweet taste locus. Nat Neurosci 4:492-498.

Nelson G, Hoon MA, Chandrashekar J, Zhang Y, Ryba NJP, Zuker CS (2001) Mammalian sweet taste receptors. Cell 106:381-390.
Nie Y, Vigues S, Hobbs JR, Conn GL, Munger SD (2005) Distinct contributions of T1R2 and T1R3 taste receptor subunits to the detection of sweet stimuli. Curr Biol 15:1948-1952.

Nissenbaum JW, Sclafani A (1987) Qualitative differences in polysaccharide and sugar tastes in the rat: a two-carbohydrate taste model. Neurosci Biobehav Rev 11:187-196.

Sainz E, Korley JN, Battey JF, Sullivan SL (2001) Identification of a novel member of the T1R family of putative taste receptors. J Neurochem 77:896-903.

Sako N, Shimura T, Komure M, Mochizuki R, Matsuo R, Yamamoto T (1994) Differences in taste responses to Polycose and common sugars in the rat as revealed by behavioral and electrophysiological studies. Physiol Behav 56:741-745.

Sclafani A (1987) Carbohydrate taste, appetite, and obesity: an overview. Neurosci Biobehav Rev 11:131-153.

Sclafani A (1991) Starch and sugar tastes in rodents: an update. Brain Res Bull 27:383-386.

Sclafani A (2004a) Oral and postoral determinants of food reward. Physiol Behav 81:773-779.

Sclafani A (2004b) The sixth taste? Appetite 43:1-3.

Sclafani A (2007) Fat and sugar flavor preference and acceptance in C57BL/6J and 129 mice: experience attenuates strain differences. Physiol Behav 90:602-611.

Sclafani A, Clyne AE (1987) Hedonic response of rats to polysaccharide and sugar solutions. Neurosci Biobehav Rev 11:173-180.

Sclafani A, Glendinning JI (2005) Sugar and fat conditioned flavor preferences in C57BL/6J and 129 mice: oral and postoral interactions. Am J Physiol Regul Integr Comp Physiol 289:R712-R720.

Sclafani A, Einberg LT, Nissenbaum JW (1987) Influence of saccharide on polycose, sucrose, and glucose intake and preference in rats. Neurosci Biobehav Rev 11:223-229.

Sclafani A, Zukerman S, Glendinning JI, Margolskee RF (2007) Fat and carbohydrate preferences in mice: the contribution of alpha-gustducin and Trpm5 taste-signaling proteins. Am J Physiol Regul Integr Comp Physiol 239:R1504-R1513.

Sclafani A, Glass DS, Margolskee RF, Glendinning JI (2010) Gut T1R3 sweet taste receptors do not mediate sucrose-conditioned flavor preferences in mice. Am J Physiol Regul Integr Comp Physiol 299:R1643-R1650.

Smith JC (2001) The history of the "Davis Rig." Appetite 36:93-98.

Spector AC, Glendinning JI (2009) Linking peripheral taste processes to behavior. Curr Opin Neurobiol 19:370-377.

Spector AC, Grill HJ (1988) Differences in the taste quality of maltose and sucrose in rats: issues involving the generalization of conditioned taste aversions. Chem Senses 13:95-113.

Spector AC, Redman R, Garcea M (1996) The consequences of gustatory nerve transection on taste-guided licking of sucrose and maltose in the rat. Behav Neurosci 110:1096-1109.

Spector AC, Markison S, St John SJ, Garcea M (1997) Sucrose vs. maltose taste discrimination by rats depends on the input of the seventh cranial nerve. Am J Physiol 272:R1210-R1218.

Treesukosol Y, Blonde GD, Spector AC (2009) T1R2 and T1R3 subunits are individually unnecessary for normal affective licking responses to polycose: implications for saccharide taste receptors in mice. Am J Physiol Regul Integr Comp Physiol 296:R855-R865.

Vigorito M, Sclafani A, Jacquin MF (1987) Effects of gustatory deafferentation on Polycose and sucrose appetite in the rat. Neurosci Biobehav Rev 11:201-209.

Xu H, Staszewski L, Tang H, Adler E, Zoller M, Li X (2004) Different functional roles of T1R subunits in the heteromeric taste receptors. Proc Natl Acad Sci U S A 101:14258-14263.

Zhao GQ, Zhang Y, Hoon MA, Chandrashekar J, Erlenbach I, Ryba NJP, Zuker CS (2003) The receptors for mammalian sweet and umami taste. Cell 115:255-266.

Zukerman S, Glendinning JI, Margolskee RF, Sclafani A (2009a) T1R3 taste receptor is critical for sucrose but not Polycose taste. Am J Physiol Regul Integr Comp Physiol 296:R866-R876.

Zukerman S, Touzani K, Margolskee RF, Sclafani A (2009b) Role of olfaction in the conditioned sucrose preference of sweet-ageusic T1R3 knockout mice. Chem Senses 34:685-694. 